\title{
Esophageal stents for anastomotic leaks and perforations
}

\author{
Jonathan D'Cunha, MD, PhD, Natasha M. Rueth, MD, Shawn S. Groth, MD, Michael A. Maddaus, MD, and \\ Rafael S. Andrade, MD
}

Objective: Intrathoracic esophageal anastomotic leaks and perforations are very morbid and challenging problems. Esophageal stents are increasingly playing an integral role in the management of these patients. Our objective was to report our experience with esophageal stent placement for anastomotic leaks and perforations and to provide a treatment algorithm.

Methods: We performed a review of patients with stent placement for esophagogastric anastomotic leaks or esophageal perforation from March 2005 to August 2009. A prospective database was used to collect data. Success was defined as endoscopic defect closure, negative esophagram, and resumption of oral intake. Failure was defined as no change in leak size or clinical signs of ongoing infection. We collected and analyzed patient demographics, diagnosis, clinical history, and poststent outcomes using descriptive statistics.

Results: Thirty-seven patients underwent esophageal stent placement for anastomotic leaks $(n=22)$ and perforations $(n=15)$. The median time from original procedure to diagnosis of leak or perforation was 6 days (0-420 days). Nineteen patients $(51 \%)$ had 21 associated procedures for source control. We placed 94 stents $($ mean $=2.7$ stents/patient); 16 patients $(43 \%)$ required more than 1 stenting procedure (mean $=1.8$ procedures/patient). The median time to restoration of esophageal integrity was 33 days (7-120 days). There were 22 successes (59\%); 2 failures were secondary to undrained abscess. Only 2 failures occurred in the last 15 patients ( $88 \%$ success). Strictures did not develop in any patients. Serious complications occurred in 3 patients (stent erosion, leak enlargement, fatal gastroaortic fistula).

Conclusions: Esophageal stents can potentially play an integral role in the management of anastomotic leaks and perforations. Success depends on appropriate procedures for source control and surgeon experience. (J Thorac Cardiovasc Surg 2011;142:39-46)

Supplemental material is available online.

Earn CME credits at

http://cme.ctsnetjournals.org

Intrathoracic anastomotic leaks postesophagectomy and esophageal perforations are a major source of morbidity $(10 \%-60 \%)$ and mortality $(4 \%-50 \%)$; furthermore, $10 \%$ to $50 \%$ of patients develop strictures requiring dilations. ${ }^{1-9}$ To date, no unified approach is available to treat these complex problems. Some investigators suggest aggressive operative intervention (eg, surgical exploration and repair

\footnotetext{
From the Division of Thoracic and Foregut Surgery, Department of Surgery, University of Minnesota, Minneapolis, Minn.

Disclosures: Authors have nothing to disclose with regard to commercial support.

Received for publication Jan 27, 2011; revisions received April 9, 2011; accepted for publication April 26, 2011.

Address for reprints: Jonathan D'Cunha, MD, PhD, Division of Thoracic and Foregut Surgery, Department of Surgery, University of Minnesota, MMC 207, 420 Delaware St SE, Minneapolis, MN 55455 (E-mail: jdcunha@umn.edu). $0022-5223 / \$ 36.00$

Copyright (c) 2011 by The American Association for Thoracic Surgery doi:10.1016/j.jtcvs.2011.04.027
}

or gastric conduit takedown with diversion) for patients with postesophagectomy intrathoracic anastomotic leak, whereas others recommend nonoperative management with total parenteral nutrition, perianastomotic drainage, and broad-spectrum antibiotics. ${ }^{5,10-15}$ Guidelines for either approach are not well defined, and most thoracic surgeons incorporate clinical judgment in the therapeutic decisionmaking process. The decision most often is based on the location and size of the leak or perforation and the patient's overall clinical condition.

In recent years, several reports have described the use of endoscopically placed esophageal stents for the treatment of leaks and perforations. ${ }^{16-37}$ These case series include heterogeneous patient populations, a variety of stent types (mostly metallic), mixed management concepts, and overall success rates of $60 \%$ to $90 \%{ }^{\mathrm{e}}{ }^{\mathrm{3} 8}$ However, the very diverse nature of published reports, including ill-defined outcome measures, creates a challenge for surgeons willing to entertain this therapeutic option for patients with esophageal intrathoracic anastomotic leaks or perforations.

The aim of the present study is to demonstrate the utility of esophageal stents in patients with esophageal intrathoracic anastomotic leaks or perforations. Further, we seek to propose a stent-based treatment algorithm for these very challenging patients. 


\section{Abbreviation and Acronym \\ $\mathrm{CT}=$ computed tomography}

\section{MATERIALS AND METHODS \\ Study Design and Patient Selection}

We performed an institutional review board-approved retrospective review of our prospectively held esophageal stent database from March 2005 to August 2009. All patients were treated at the University of Minnesota. Esophageal anastomotic leak or perforation was diagnosed by one or several diagnostic tests: esophagram, endoscopy with fluoroscopy and intraoperative contrast injection, and computed tomography (CT) imaging of the neck, chest, and abdomen. We excluded patients with anastomotic leaks secondary to gastric tip necrosis; gastric conduit necrosis; leaks or perforations within $2 \mathrm{~cm}$ of the cricopharyngeus muscle; perforated esophageal cancer; and tracheoesophageal fistula secondary to a leak or perforation. Patients who were managed conservatively with low output leaks were also excluded from this study.

\section{Esophageal Stent Placement}

All stents were placed by thoracic surgeons with the patient in the operating room, under general anesthesia, and in the supine position with the head of the bead elevated 30 to 45 degrees. Endoscopy and fluoroscopy were used. When there was doubt about the location and size of the leak, these were evaluated with intraoperative contrast injection (iodixanol [Visipaque; GE Healthcare Inc, Princeton, NJ]), which is safer in case of aspiration. We then passed a stiff-shaft guidewire $(0.035 \mathrm{~mm}, 260 \mathrm{~cm})$ through the endoscope into the distal stomach or first portion of the duodenum, removed the endoscope, and deployed the esophageal stent(s) over the wire using fluoroscopic guidance. We used fully covered nitinol stents (ALIMAXX-E; Alveolus, Charlotte, NC) or silicone stents (Polyflex; Boston Scientific, Natick, Mass). The decision to place 1 or 2 stents depended on the cause and properties of the leak or perforation as detailed below.

\section{Esophagogastric Anastomotic Leak}

In patients with an esophagogastric anastomotic leak, the esophagus is of normal caliber, and the gastric conduit has a significantly larger diameter than the esophagus. A conventional stent with only a proximal flare will fit securely in the esophagus but will not completely seal the leak: The size discrepancy between the stent and the stomach allows gastric contents to reflux around the distal end of stent and continue leaking through the anastomotic defect. To minimize this problem, we used a double-stent, double-flare (dumbbell) technique: The largest available Polyflex silicone stent (diameter: 21-mm shaft, 25-mm flare) was placed upside down across the anastomosis so that the flare was in the stomach (only a Polyflex stent can be easily loaded upside down); next, we placed a second stent (any fully covered type, 21-23-mm shaft) upside up into the first stent, creating a doubleflare (dumbbell) stent arrangement (Figure 1). We developed the dumbbell technique so that the distal flare would reduce the possibility of peri-stent reflux in the conduit (Figure 2). We believe the use of the double flare strategy minimizes migration and provides better leak occlusion. We recognize this is not the only potential strategy, particularly in light of the more recent availability of double-flared, fully-covered stents in the United States; however, during the time period of this study, double-flared stents were not accessible for clinical practice.

\section{Esophageal Perforation}

Patients with an esophageal perforation often have an associated stricture; thus, we chose a stent diameter that was appropriate for the particular situation. Although a single stent was mainly used in this setting, selected patients required the 2-stent, dumbbell technique described above to maximize the seal for control of the perforation.

\section{Additional Management Considerations}

As we gained experience, we increasingly used long stents $(12-15 \mathrm{~cm})$ to minimize migration. After stent placement, we again injected contrast to verify leak occlusion. Nasogastric tubes were not routinely used. Additionally, we performed any indicated drainage procedures for source control (neck exploration and drainage, mediastinal irrigation, video-assisted thoracoscopy, thoracotomy) depending on the clinical status and imaging studies.

\section{Stent Surveillance and Patient Follow-up}

Patients continued to receive intravenous broad-spectrum antibiotics and antifungal agents postoperatively. We obtained routine postoperative chest $\mathrm{x}$-rays in the postanesthesia care unit to document stent position and routinely obtained daily chest $\mathrm{x}$-rays for at least 72 hours to assess position and screen for stent migration. In addition to performing an esophagram intraoperatively, we repeat the esophagram in patients who are able to swallow at 24 to 48 hours after stent placement. If we find absence of ongoing leak on this initial study, we initiate oral intake with clear liquids. Although our goal was to provide oral intake as soon as able, we also provided supplemental nutrition to patients as indicated. All patients undergoing esophagectomy had jejunostomy tubes. The patients with spontaneous perforations all underwent gastrostomy or jejunostomy tube placement if unable to take oral intake within 5 days. We generally obtained an esophagram within 2 to 4 weeks of stent placement once the patient had passed a swallow examination by our speech pathologists (Gastrografin [Bracco Diagnostics Inc, Princeton, NJ], barium, or both). All patients required routine aspiration precautions, and any stent across the gastroesophageal junction mandated high-dose proton pump inhibitor therapy. We routinely planned stent removal after 3 to 4 weeks to allow for healing of the defect and to monitor for gastric conduit erosion related to the distal end of the stent. We then reassessed defects endoscopically and fluoroscopically with contrast injection and, if needed, replaced stents. This was individualized by patient according to cause, size, and location of the defect; nutritional status; and resolution of infection.

\section{Outcomes}

Success was defined as endoscopic defect closure, negative esophagram, and resumption of oral intake without signs of clinical infection. Failure was defined as no change in leak size or ongoing infection. Patients deemed as failures underwent stent removal and operative intervention. Once discharged from the hospital, outpatients were routinely assessed by esophagram and CT scan, if indicated.

\section{Data Analysis}

All clinical parameters were documented prospectively using our database. Continuous data for our investigation were reported as mean (or median) \pm standard deviation.

\section{RESULTS}

During the 4-year evaluation period, 37 patients were identified to have esophageal anastomotic leaks or esophageal perforations. The mean age of patients was 60 years (range, 19-83 years); 26 were male and 11 were female. There were $22(59.5 \%)$ anastomotic leaks and 15 $(40.5 \%)$ perforations. Table 1 delineates the cause of esophageal perforations. The anastomotic leaks occurred in 20 patients who had undergone esophagectomy with intrathoracic anastomosis and 1 patient with a cervical anastomosis. 


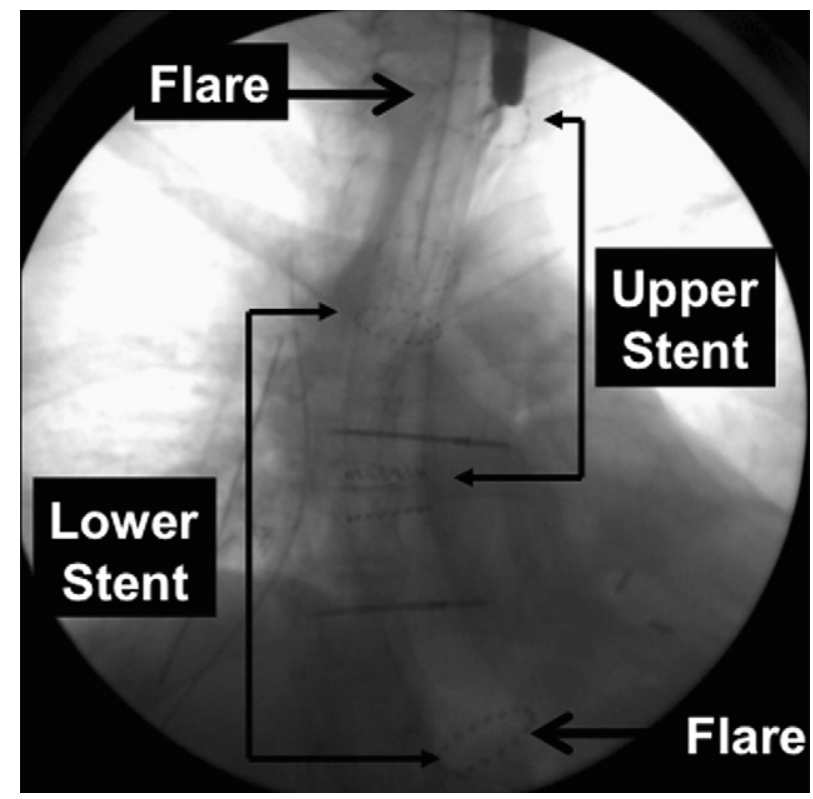

FIGURE 1. Intraoperative fluoroscopic image. This represents the "dumbbell technique" of applying Polyflex stents in overlapping fashion. The leak was located between the 2 needle markers.

Among patients who had undergone esophagectomy with anastomotic leaks, $10(47.6 \%)$ had undergone preoperative radiation or chemotherapy. The diagnosis of clinically suspected leaks was established via an esophagram. One addi-

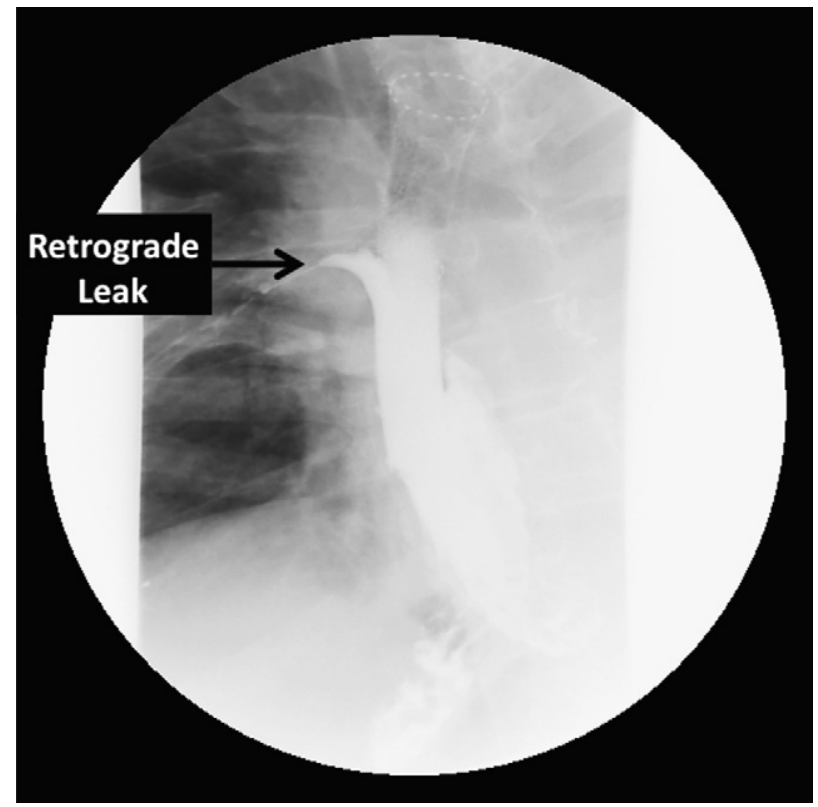

FIGURE 2. Retrograde reflux around stent resulting in persistent leak. Intraoperative fluoroscopic contrast study from a patient with a leak postesophagectomy. A single Polyflex esophageal stent was placed across the leak, and retrograde reflux of contrast was seen at the distal portion of the stent. There was a persistent leak in this patient, as seen in the contrast image. Deployment of our stenting technique as used in Figure 1 solved this issue.
TABLE 1. Original procedures performed in patients presenting with esophageal perforation

\begin{tabular}{lcc}
\hline \multicolumn{1}{c}{ Procedure } & No. & $\%$ \\
\hline Collis gastroplasty & 1 & 6.7 \\
Laparoscopic gastric band & 1 & 6.7 \\
Thoracoscopic leiomyoma resection & 1 & 6.7 \\
Laparoscopic Heller myotomy & 1 & 6.7 \\
Foreign body extraction & 3 & 20 \\
Stricture dilation & 4 & 26.7 \\
Percutaneous gastrostomy tube & 1 & 6.7 \\
Mediastinoscopy & 1 & 6.7 \\
Spontaneous perforation & 2 & 13.3 \\
Total & 15 & 100 \\
\hline
\end{tabular}

tional patient had an anastomotic leak after total gastrectomy. All patients undergoing stent treatment were not able to be managed conservatively because of lack of source control.

The median time from the original procedure to the diagnosis of leak or perforation was 6 days (range, 0-420 days) (leak median, 7.5 days; range, 1-420; perforation median, 2 days; range, $0-15$ ). The outlying patient diagnosed 420 days postoperatively had undergone esophagectomy followed 6 months later by attempted stricture dilation complicated by perforation at an out-of-state institution. Eighteen patients $(48.6 \%)$ were stented the same day their leak or perforation was diagnosed; another 3 patients $(8.1 \%)$ were stented within the first 24 hours. Importantly, 19 patients $(51.4 \%)$ had an additional 21 procedures performed to achieve source control (Table 2). These 19 patients requiring additional drainage procedures included 10 $(60.0 \%)$ with leaks and $9(45.4 \%)$ with perforations. Chest drainage and decortication were the most common associated procedures $(\mathrm{n}=14,66.7 \%)$.

We placed a total of 94 stents (mean $=2.7$ stents/patient; Polyflex-69, Alimaxx-24, and 1 partially covered nitinol stent [Ultraflex; Boston Scientific]). The breakdown of the mean number of stents required by subgroup included 3.0/patient for leaks and 2.0/patient for perforations. Sixteen patients $(43.2 \%)$ required more than 1 stenting procedure (mean $=1.8$ stenting procedures/patient; 14 days to 21 days after initial stent placement); half of re-stenting procedures were performed for scheduled, routine reevaluation of the leak or perforation, and half were undertaken for stent-related complications (Table 3). In the leak subgroup, 16 of 22 patients had stents placed using the 2-stent approach. In the perforation subgroup, patients typically had 1 stent placed to control the leak, and only 2 of 15 patients required the double-stenting technique. Re-stenting procedures were required in 10 patients $(45.4 \%)$ with leaks and in 6 patients $(40.0 \%)$ with perforations. Importantly, no patients required dilation for esophageal stricture after resolution and stent removal, with a mean follow-up time of 41.6 months (range, 18.7-67.0 months). Stent migration 
TABLE 2. Source control procedures performed

\begin{tabular}{lr}
\hline \multicolumn{1}{c}{ Procedure } & No. \\
\hline Thoracotomy with decortication & 6 \\
VATS with decortication & 8 \\
Percutaneous drain placement & 1 \\
Neck exploration and drainage & 4 \\
Laparoscopic exploration & 2 \\
Total & 21 \\
\hline VATS, Video-assisted thoracoscopic surgery. &
\end{tabular}

was the most common stent-related complication, occurring in $16.2 \%$ of patients (4 [18.2\%] leaks, 2 [13.3\%] perforations). Serious complications occurred in 3 patients (stent erosion, leak enlargement, and death from gastroaortic fistula). All of these complications occurred in patients postesophagectomy. None of these patients had been treated with preoperative radiation or chemotherapy. Two of the three patients had stents placed via dumbbell technique. Their initial management and hospital courses were not atypical from those of the rest of the patients. The development of the gastroaortic fistula was a rare and lethal complication of esophageal stent placement, and our detailed report of this devastating clinical scenario serves as a warning of caution. ${ }^{\text {e39 }}$ In this series, the overall mortality directly related to esophageal leak was $13.5 \%$ (5 patients). The deaths occurred in the patient with gastroaortic fistula; in 1 patient with stenting success and unrelated multisystem organ failure, ultimately placed on comfort care by family members; and in 3 patients with stenting failures, placed in hospice in the face of uncontrolled sepsis. Four of these deaths occurred in patients with anastomotic leaks (18.1\% mortality in this subgroup), and 1 death was in a patient with spontaneous perforation (6.7\% mortality).

Twenty-two patients $(59.5 \%)$ were considered a stent success by having complete resolution of their leak or perforation within a median time of 33 days (range, 7-120 days). This included 13 patients $(59.1 \%)$ with esophagogastric anastomotic leak, whose median time to resolution was 40.5 days (range, 22-120 days); for patients with perforation, the median time for resolution was 27 days (range, $5-41$ days), with success in $9(60.0 \%)$. The largest anastomotic leak treated successfully encompassed approximately $50 \%$ of the original anastomotic circumference (Figure 3). For these 22 successes, the median time to oral intake was 3 days (range, 0-69 days). For leaks successfully treated with

TABLE 3. Stent-related complications

\begin{tabular}{lcc}
\hline \multicolumn{1}{c}{ Complication } & No. & \% of total cases $(\mathbf{n}=\mathbf{3 7})$ \\
\hline Stent migration & 6 & 16.2 \\
Enlargement of original leak & 1 & 2.7 \\
Stent erosion & 1 & 2.7 \\
Gastroaortic fistula & 1 & 2.7 \\
Total & 9 & 24.3 \\
\hline
\end{tabular}

stents, the median time to oral intake was 6 days (range, 0-69 days). For perforations successfully treated, the median time to oral intake was 3 days (range, $1-43$ days). Reasons for stent failure are listed in Table 4; the major reason for unsuccessful stent placement was nonseal of esophageal leak or perforation requiring definitive surgical intervention. Notably, we achieved an $88.2 \%$ success rate for closure of leak or perforation in the 15 most recently treated patients (17 total). As our experience grew, 9 patients $(24.3 \%)$ with an immediately diagnosed iatrogenic perforation underwent stent placement, esophagogram the next day, and started oral intake on postoperative day 1 . They were discharged at a median of 5 days (range, 2-33 days) on oral antibiotics and eating a mechanical soft diet.

\section{DISCUSSION}

Postesophagectomy anastomotic leaks and esophageal perforations are serious morbid events. Regardless of the cause and clinical condition of the patient, the principles of management are standardized: resuscitation, broadspectrum antimicrobial therapy, drainage of contaminated areas, and source control (control or closure of the defect). Despite adherence to these principles and advances in intensive unit care, the morbidity $(10 \%-60 \%)$ and mortality $(4 \%-50 \%)$ associated with esophageal leaks and perforations are still very high; furthermore, strictures requiring dilations develop in $10 \%$ to $50 \%$ of patients. ${ }^{1-9}$ Our report presents the 2 patient populations, with anastomotic leaks and perforations, as one group because the principles of management outlined above are the same for both. Additionally, either event alone is uncommon; hence, other investigators have also mixed these 2 patient populations in the same manner to accumulate a series of relevant size. ${ }^{16,24}$

Our findings indicate that esophageal stent placement for leaks and perforations facilitates source control, prevents stricture formation, and, in select cases, allows for early oral intake. However, success depends on a uniform approach that focuses on appropriate patient selection, proper stent placement technique, thorough drainage procedures, and meticulous postoperative care.

\section{Patient Selection}

We place a stent in any patient with an esophageal anastomotic leak or perforation following the algorithm outlined in Figure 4. Of note, we have not had any problems performing endoscopy and stent placement for anastomotic leaks as early as the third postoperative day in patients postesophagectomy. Exceptions to stenting as primary therapy for this problem include patients with gastric tip or conduit necrosis, leaks or perforations within $2 \mathrm{~cm}$ of the cricopharyngeus muscle, perforated cancer, and tracheoesophageal fistula secondary to a leak or a perforation. Patients with severe conduit ischemia generally require revision or 

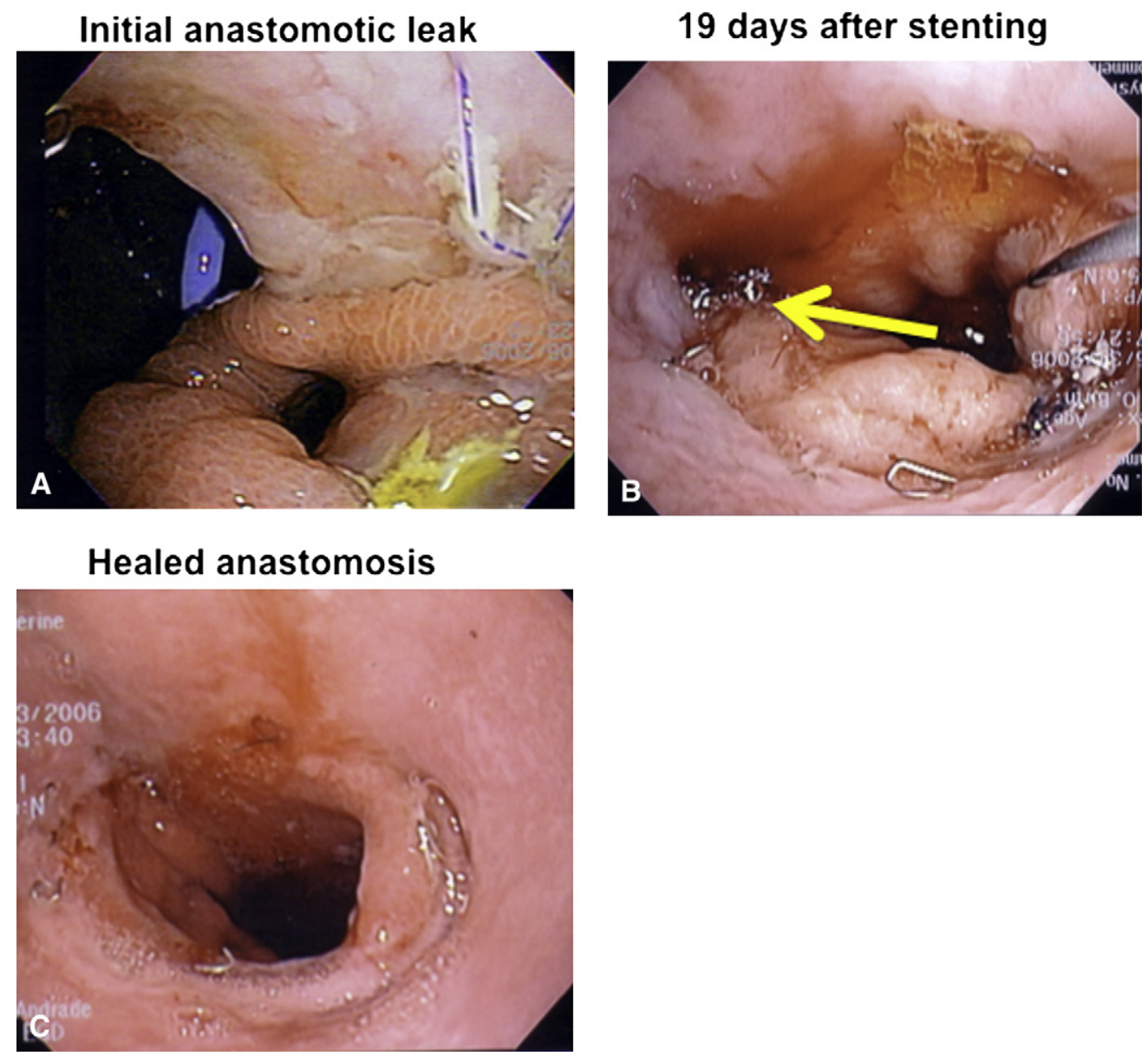

FIGURE 3. Endoscopic progression of leak closure. A, Dramatic postesophagectomy anastomotic leak draining directly into the left pleural space; a blue pleural pig-tail catheter is clearly visible. B, Near-complete healing 19 days after stent placement and left decortication, with only a pinpoint leak remaining (arrow). C, Stents were replaced at day 19 and definitively removed on day 32; an esophagram confirmed complete resolution.

diversion; a stent across or immediately underneath the cricopharyngeus is extremely uncomfortable. Patients with a perforated esophageal cancer should preferably undergo resection because a perforated tumor is unlikely to seal with a stent; however, this decision should be individualized, and this may be adequate therapy in the palliative setting. Patients with a tracheoesophageal fistula secondary to a leak or perforation are extremely complex and should only

TABLE 4. Stent-related outcomes

\begin{tabular}{lrr}
\hline \multicolumn{1}{c}{ Outcome } & n & $\%$ \\
\hline Success & 22 & 59.5 \\
Reason for failure & & \\
$\quad$ Nonseal of leak & 9 & 24.3 \\
Stent erosion & 2 & 5.4 \\
Kinked stent & 1 & 2.7 \\
Stent malposition & 1 & 2.7 \\
Early withdrawal of care (multisystem organ failure) & 1 & 2.7 \\
Gastroaortic fistula & 1 & 2.7 \\
Total & 37 & 100 \\
\hline
\end{tabular}

be considered for esophageal stent placement as a bridge to a definitive repair. Although we had 1 patient with total gastrectomy in our series, in general, we believe an esophagojejunostomy leak should have an individualized approach that favors not undergoing stent placement, because the small bowel wall is susceptible to stent-induced erosion and perforation.

One must be prepared to perform more extensive interventions, such as mediastinal drainage or decortication, if the leak or perforation has been present for more than 24 hours and there is clinical or radiologic evidence of deep space infection. After considering the above exclusions, 2 key principles dictate whether a patient is an appropriate candidate for esophageal stent placement: luminal diameter and vertical orientation. If the diameter of the esophagus or conduit is too large, no stent will be large enough to cause apposition and sealing; if a gastric conduit is angled, then the distal portion of the stent will initially be occluded by the gastric wall and will eventually perforate the conduit. 


\section{ESOPHAGEAL LEAK OR PERFORATION}

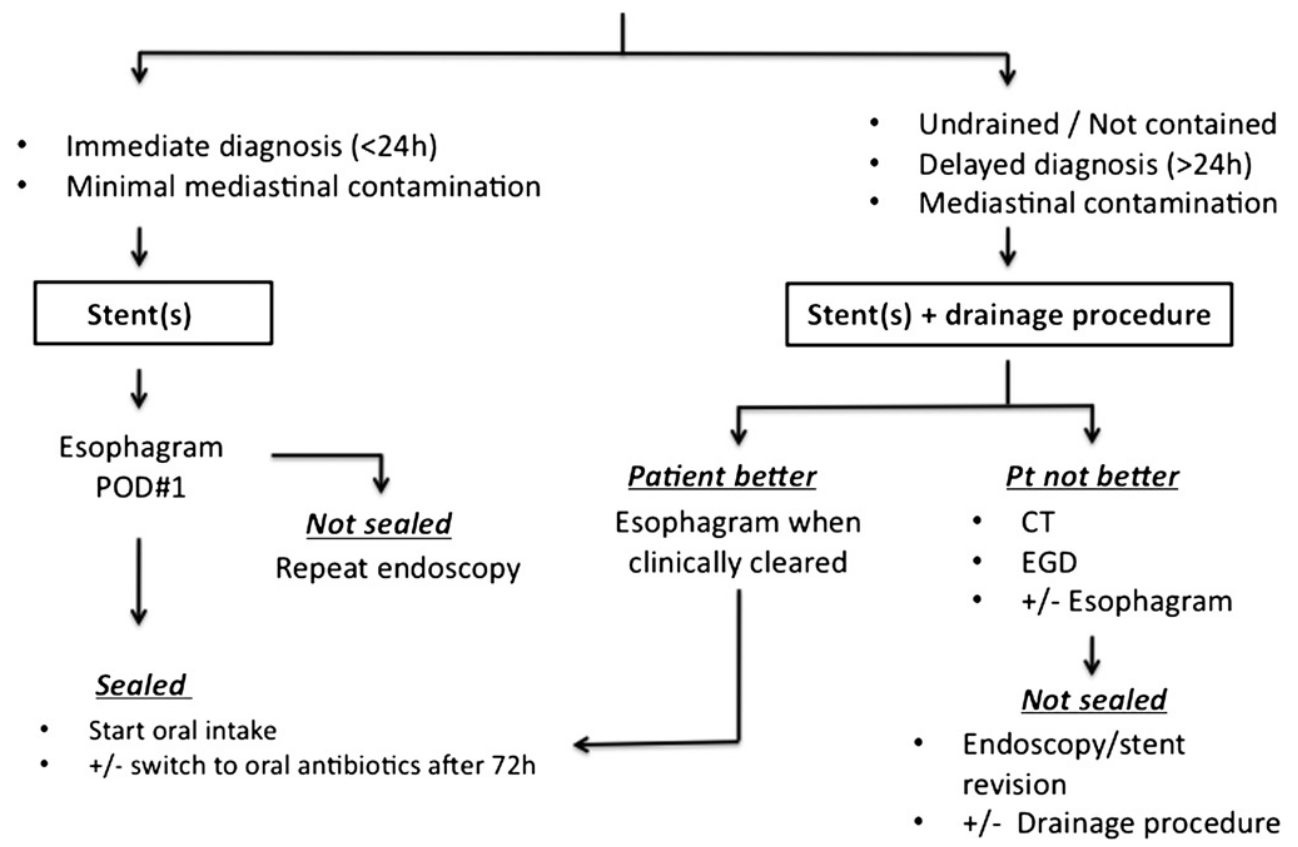

FIGURE 4. Treatment algorithm for esophageal stent placement in patients with esophageal leaks or perforations. $C T$, Computed tomography; EGD, esophagogastroduodenoscopy; $P O D$, postoperative day.

\section{Stent Placement Technique}

Successful stent placement for an esophageal anastomotic leak or perforation depends on several technical considerations:

(1) Stent choice: We use only fully covered nitinol or silicone stents and preferably deploy them with the dumbbell technique. Our decision to use this technique prior to the availability of fully covered, double-flared stents was based entirely on our empirical observations of improved leak sealing in patients postesophagectomy. In our experience, the procedure is not more challenging than single-stent placement. Recently, however, a fully covered, double-flared nitinol stent has been released in the United States (Wallflex; Boston Scientific). This has the potential to obviate the need for dumbbell stent placement and is our current esophageal stent of choice for leaks and perforations. We believe that using long stents with a large diameter improves sealing and reduces migration, and this is the principle to which one must adhere. Our migration rate was only $16.2 \%$, which compares favorably to reported migration rates as high as $63 \%$ in some series. ${ }^{\text {e }}{ }^{0}$

(2) Intraoperative seal: We leave a stent in place only if we can confirm a satisfactory intraoperative seal; otherwise, a stent needs to be repositioned or removed altogether. An improperly placed stent provides no source control and only adds to the risk of complications (ie, erosion, perpetuation of the leak, aspiration, and ob- struction). Our intraoperative technical success was $95 \%$, consistent with that of other recent reports. ${ }^{16, \mathrm{e} 41}$

\section{Additional Procedures}

If indicated for optimum source control, additional drainage procedures following basic surgical principles are imperative. In our experience, $51 \%$ of patients required an additional procedure at the time of esophageal stent placement. Of note, $52.3 \%$ of patients (11/21) who required deep space drainage underwent a minimally invasive procedure (video-assisted thoracoscopy, percutaneous drainage, or laparoscopy). However, we do not hesitate to convert to an open procedure if needed. The patient's outcome depends on the quality of the initial stent placement technique in combination with an appropriate drainage procedure if indicated.

\section{Postoperative Management}

Certain aspects of postoperative management deserve emphasis:

(1) Radiologic follow-up: Daily chest radiographs are obtained at least in the first 72 hours to watch for stent migration. Prior to oral intake, patients undergo an esophagram when clinically appropriate. The timing of this evaluation varies significantly. Although an initially critically ill patient may take several weeks to recover sufficiently enough to undergo a swallow evaluation by a speech pathologist prior to attempting an esophagram, patients who present within the first 24 hours of perforation with 


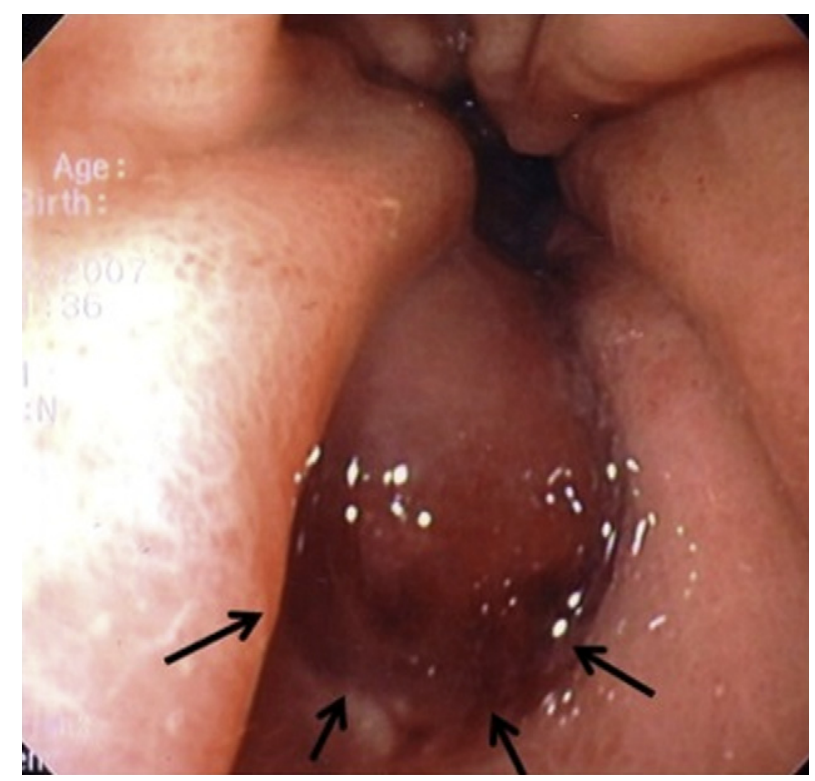

FIGURE 5. Gastric conduit mucosal erosion. After removal of a stent that had been in place for 3 weeks, mucosal erosion was seen. The arrows point to the area where the distal edge of the stent had been in contact causing mucosal irritation. If stent replacement is required, careful attention to this area is made and the replacement stent is placed proximally or distally to the injured region.

minimal contamination undergo an esophagram the day after stent placement. Once an esophagram has demonstrated sealing, patients may then start oral intake (clear liquids). In our study population, 9 patients started oral intake shortly after stent placement and were discharged within 4 days on oral antibiotics.

On occasion, we demonstrate proper seal intraoperatively, but some distal peri-stent refluxate leaks when the patient undergoes a formal esophagram. Under these circumstances, we leave the stents in place if we see that the leak is smaller than on initial presentation and the patient is improving clinically; we will then repeat the esophagram after 1 or 2 more weeks of continued clinical improvement. Any indication of clinical deterioration mandates radiologic investigation, preferably CT scan, or even immediate reintervention. We liberally return deteriorating patients to the operating room for endoscopic, fluoroscopic, and, if necessary, operative reassessment.

(2) Stent exchange: We routinely remove the initial stent(s) within 3 to 4 weeks of placement and reevaluate the leak or perforation with endoscopy and fluoroscopy. We adopted this approach early in our experience, because we became concerned about gastric-conduit mucosal erosion over time at the distal end of the stent. In contrast with other recent reports, all stents in our series were easily removed without complications. ${ }^{\text {e42 }}$ If we demonstrate sealing at the time of stent reevaluation, but we believe the patient is at risk for stricture formation (eg, a patient who had an iatrogenic perforation for a preexisting benign stricture), we will replace a stent and leave it in place for another 4 weeks. Our approach resulted in the use of 2.7 stents per patient. If we replace a stent in a patient with an esophagogastric anastomotic leak, we ensure that the distal end of the stent is at a different level than the initial stent(s) so that mucosal erosion occurs in a different place and the previous area of damage is allowed to heal (Figure 5).

(3) Antimicrobial therapy: All patients receive broadspectrum antibiotics and antifungals, and we tailor therapy according to clinical course and culture results. Antibiotics are discontinued on determination of success (endoscopic defect closure, negative esophagram, and resumption of oral intake without signs of clinical infection).

A number of investigators have reported the successful application of endoluminal stents for esophageal leaks and perforations on heterogeneous patient populations, using a range of stent types and variable management strategies. ${ }^{16-\mathrm{e} 37}$ Results have been promising; however, no unified approach has been proposed. In a recently published series of 32 patients with leaks or perforations, Tuebergen and colleagues ${ }^{16}$ reported an initial intraoperative seal rate of $78 \%$, a stent complication rate of $28 \%$, a $15 \%$ mortality rate, an overall success rate of $59 \%$, and a stricture rate of $9 \%$. Freeman and colleagues ${ }^{22,23, e 41}$ have published some of the most comprehensive reports on this subject. In their most recent case series, they effectively placed stents in 19 patients with spontaneous perforation of the esophagus. Leak occlusion occurred in 17 patients $(89 \%)$, and 15 patients $(79 \%)$ started oral intake within 72 hours of stent placement. Stents were removed at a mean of 20 days after placement with an overall success rate of $79 \%$. ${ }^{40}$

In our report, we achieved successful intraoperative leak or perforation occlusion in $95 \%$ of patients. We observed a stent-related complication rate of $24 \%$, a $14 \%$ overall mortality rate, an overall success rate of $60 \%$, and no strictures. The rate of complete resolution improved as we gained experience, reaching $88 \%$ success in our last 15 patients ( 2 failures). We believe that the high success rate in the latter half of our series is a direct result of using our uniform management algorithm (Figure 4), which was established through our experience and progression on a learning curve with stent-based therapy for esophageal leaks and perforations. Patients with esophagogastric anastomotic leaks tended to take longer to achieve resolution than patients with an esophageal perforation (40.5 vs 21 days); this is most likely explained by patient-related factors (eg, malnutrition, systemic inflammation, immunosuppression, and neoadjuvant therapy), a larger lumen-to-stent size discrepancy, and more tissue ischemia in patients post-esophagectomy. 
Although our approach is somewhat labor-intensive, endoscopic surveillance is a critical component to ensure that these patients are making satisfactory progress. Interestingly, none of our successfully treated patients developed a stricture that required dilation, probably because the stent acts as a mold during healing and scarring. The significance of the absence of strictures in this population is highlighted by comparison with our $10 \%$ incidence of strictures requiring dilation after esophagectomy in patients without an anastomotic leak. Our results with esophageal stent placement for anastomotic leaks and perforations, as well as the results of others, ${ }^{16,22,23, \mathrm{e} 26, \mathrm{e} 30, \mathrm{e} 38, \mathrm{e} 40}$ compare favorably with the overall results of the traditional management of these patients. ${ }^{\text {e38 }}$

\section{Study Limitations}

We acknowledge that our study is not without limitations. We have presented a retrospective review of a small and heterogeneous group of patients with an uncommon clinical problem. This type of case series also runs the risk of selection bias, although we tried to mitigate this by providing clear selection criteria. A comparison group of patients without stent therapy would be beneficial to emphasize our findings; unfortunately, we cannot provide such a group, because stent therapy has become our standard of care for this patient population. However, the series reported consists of a number of individuals in our earlier stent experience who failed stentless management strategies prior to successful treatment with stenting, thereby essentially serving as their own matched controls. One such example is a man whose postesophagectomy leak was identified on postoperative day 3 , with unsuccessful attempts at stentless management for 8 weeks. The problem was resolved within 3 weeks of stent therapy. Further, not only do the stents seem to expedite resolution in such cases, but also these patients are able to take oral nutrition at an earlier time point than those undergoing stentless therapies, an advantage that should not be overlooked. One of the main goals of stent placement is to resume oral intake as soon as possible, a very important quality-of-life consideration. Consequently, a patient with a small or contained leak without evidence of uncontrolled deep space infection, who cannot eat for medical reasons (eg, respiratory failure, aspiration), would not benefit from stent placement.

\section{CONCLUSIONS}

Despite these limitations, our series is one of the largest reported to date, and we provide a treatment algorithm that includes proper patient selection, meticulous stent placement technique, aggressive drainage of deep space infection, broad-spectrum antimicrobial therapy, and intense postoperative care. Our algorithm and experience strongly support the serious consideration of a therapeutic paradigm shift in this challenging patient population, and future studies are clearly warranted.

\section{References}

1. Briel JW, Tamhankar AP, Hagen JA, et al. Prevalence and risk factors for ischemia, leak, and stricture of esophageal anastomosis: gastric pull-up versus colon interposition. J Am Coll Surg. 2004;198:536-42.

2. Young MM, Deschamps C, Trastek VF, et al. Esophageal reconstruction for benign disease: early morbidity, mortality, and functional results. Ann Thorac Surg. 2000;70:1651-5.

3. Vigneswaran WT, Trastek VF, Pairolero PC, et al. Transhiatal esophagectomy for carcinoma of the esophagus. Ann Thorac Surg. 1993;56:838-46.

4. Young MM, Deschamps C, Allen MS, et al. Esophageal reconstruction for benign disease: self-assessment of functional outcome and quality of life. Ann Thorac Surg. 2000;70:1799-802.

5. Crestanello JA, Deschamps C, Cassivi SD, et al. Selective management of intrathoracic anastomotic leak after esophagectomy. J Thorac Cardiovasc Surg. 2005; 129:254-60.

6. Parekh K, Iannettoni MD. Complications of esophageal resection and reconstruction. Semin Thorac Cardiovasc Surg. 2007;19:79-88.

7. Kent MS, Schuchert M, Fernando H, Luketich JD. Minimally invasive esophagectomy: state of the art. Dis Esophagus. 2006;19:137-45.

8. Alanezi K, Urschel JD. Mortality secondary to esophageal anastomotic leak. Ann Thorac Cardiovasc Surg. 2004;10:71-5.

9. Eroglu A, Turkyilmaz A, Aydin Y, et al. Current management of esophageal perforation: 20 years experience. Dis Esophagus. 2009;22:374-80.

10. Wehrmann T, Stergiou N, Vogel B, et al. Endoscopic debridement of paraesophageal, mediastinal abscesses: a prospective case series. Gastrointest Endosc. 2005; 62:344-9.

11. Amir AI, van Dullemen H, Plukker JT. Selective approach in the treatment of esophageal perforations. Scand J Gastroenterol. 2004;39:418-22.

12. Brinster CJ, Singhal S, Lee L, et al. Evolving options in the management of esophageal perforation. Ann Thorac Surg. 2004;77:1475-83.

13. Muir AD, White J, McGuigan JA, et al. Treatment and outcomes of oesophageal perforation in a tertiary referral centre. Eur J Cardiothorac Surg. 2003;23: 799-804.

14. Page RD, Shackcloth MJ, Russell GN, Pennefather SH. Surgical treatment of anastomotic leaks after oesophagectomy. Eur J Cardiothorac Surg. 2005;27:337-43.

15. Sauvanet A, Baltar J, Le Mee J, Belghiti J. Diagnosis and conservative management of intrathoracic leakage after oesophagectomy. Br J Surg. 1998;85:1446-9.

16. Tuebergen D, Rijcken E, Mennigen R, et al. Treatment of thoracic esophageal anastomotic leaks and esophageal perforations with endoluminal stents: efficacy and current limitations. J Gastrointest Surg. 2008;12:1168-76.

17. Adam A, Watkinson AF, Dussek J. Boerhaave syndrome: to treat or not to treat by means of insertion of a metallic stent. J Vasc Interv Radiol. 1995;6:741-6.

18. Blackmon SH, Santora R, Schwarz P, et al. Utility of removable esophageal covered self-expanding metal stents for leak and fistula management. Ann Thorac Surg. 2010;89:931-7.

19. Chung MG, Kang DH, Park DK, et al. Successful treatment of Boerhaave's syndrome with endoscopic insertion of a self-expandable metallic stent: report of three cases and a review of the literature. Endoscopy. 2001;33:894-7.

20. Eubanks PJ, Hu E, Nguyen D, et al. Case of Boerhaave's syndrome successfully treated with a self-expandable metallic stent. Gastrointest Endosc. 1999;49:780-3.

21. Fischer A, Thomusch O, Benz S, et al. Nonoperative treatment of 15 benign esophageal perforations with self-expandable covered metal stents. Ann Thorac Surg. 2006;81:467-72.

22. Freeman RK, Ascioti AJ, Wozniak TC. Postoperative esophageal leak management with the Polyflex esophageal stent. J Thorac Cardiovasc Surg. 2007;133: 333-8.

23. Freeman RK, Van Woerkom JM, Ascioti AJ. Esophageal stent placement for the treatment of iatrogenic intrathoracic esophageal perforation. Ann Thorac Surg. 2007;83:2003-8.

24. Gelbmann CM, Ratiu NL, Rath HC, et al. Use of self-expandable plastic stents for the treatment of esophageal perforations and symptomatic anastomotic leaks. Endoscopy. 2004;36:695-9.

25. Hunerbein M, Stroszczynski C, Moesta KT, Schlag PM. Treatment of thoracic anastomotic leaks after esophagectomy with self-expanding plastic stents. Ann Surg. 2004;240:801-7. 


\section{References}

e26. Johnsson E, Lundell L, Liedman B. Sealing of esophageal perforation or ruptures with expandable metallic stents: a prospective controlled study on treatment efficacy and limitations. Dis Esophagus. 2005;18:262-6.

e27. Karbowski M, Schembre D, Kozarek R, et al. Polyflex self-expanding, removable plastic stents: assessment of treatment efficacy and safety in a variety of benign and malignant conditions of the esophagus. Surg Endosc. 2008;22: 1326-33

e28. Kauer WK, Stein HJ, Dittler HJ, Siewert JR. Stent implantation as a treatment option in patients with thoracic anastomotic leaks after esophagectomy. Surg Endosc. 2008;22:50-3.

e29. Koch S, Weber A, Fein F, et al. Esophageal stents as a salvage therapy for nonmalignant iatrogenic esophageal perforations. Gastroenterol Clin Biol. 2005; 29:735-9.

e30. Langer FB, Wenzl E, Prager G, et al. Management of postoperative esophageal leaks with the Polyflex self-expanding covered plastic stent. Ann Thorac Surg. 2005;79:398-404

e31. Nguyen NT, Mailey BA, Hinojosa MW, Chang K. Natural orifice management of anastomotic leaks after minimally invasive esophagogastrectomy. Surg Innov. 2008;15:249-52.

e32. Nowakowski P, Ziaja K, Ludyga T, et al. Self-expandable metallic stents in the treatment of post-esophagogastrostomy/post-esophagoenterostomy fistula. Dis Esophagus. 2007;20:358-60.

e33. Ott C, Ratiu N, Endlicher E, et al. Self-expanding Polyflex plastic stents in esophageal disease: various indications, complications, and outcomes. Surg Endosc. 2007;21:889-96.

e34. Petruzziello L, Tringali A, Riccioni ME, et al. Successful early treatment of Boerhaave's syndrome by endoscopic placement of a temporary self-expandable plastic stent without fluoroscopy. Gastrointest Endosc. 2003;58:608-12.

e35. Profili S, Feo CF, Cossu ML, et al. Effective management of intrathoracic anastomotic leak with covered self-expandable metal stents. Report on three cases. Emerg Radiol. 2008;15:57-60.

e36. Schubert D, Scheidbach H, Kuhn R, et al. Endoscopic treatment of thoracic esophageal anastomotic leaks by using silicone-covered, self-expanding polyester stents. Gastrointest Endosc. 2005;61:891-6.

e37. Siersema PD, Homs MY, Haringsma J, et al. Use of large-diameter metallic stents to seal traumatic nonmalignant perforations of the esophagus. Gastrointest Endosc. 2003;58:356-61.

e38. Sharma P, Kozarek R. Role of esophageal stents in benign and malignant diseases. Am J Gastroenterol. 2010;105:258-73; quiz 274.

e39. Whitelock D, Maddaus M, Andrade R, D’Cunha J. Gastroaortic fistula: a rare and lethal complication of esophageal stenting after esophagectomy. J Thorac Cardiovasc Surg. 2010;140:e49-50.

e40. Pennathur A, Chang AC, McGrath KM, et al. Polyflex expandable stents in the treatment of esophageal disease: initial experience. Ann Thorac Surg. 2008;85: 1968-73.

e41. Freeman RK, Van Woerkom JM, Vyverberg A, Ascioti AJ. Esophageal sten placement for the treatment of spontaneous esophageal perforations. Ann Thorac Surg. 2009;88:194-8.

e42. van Heel NC, Haringsma J, Spaander MC, et al. Short-term esophageal stenting in the management of benign perforations. Am J Gastroenterol. 2010;105: 1515-20. Epub 2010 Mar 16. 